\title{
An Approach to Assessing Faculty Use of Locally Loaded Databases
}

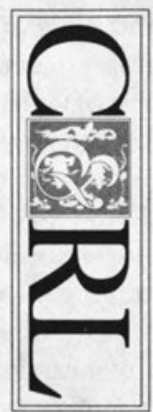

\section{Joan B. Fiscella and Edward Proctor}

\begin{abstract}
A survey was used to study faculty use of, preferences for, and satisfaction with either the SPIRES/Prism or the BRS MENTOR interfaces for locally loaded Educational Resources Information Center (ERIC). The findings showed no significant difference in faculty preferences for one or the other interface; however, faculty use of locally loaded databases was associated with having a campus computer account. The study also looked at use of other locally loaded databases by faculty in education and other social science disciplines. The limitations of the survey are addressed.
\end{abstract}

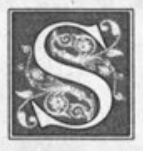

tudies of online database use have shown that faculty have given a mixed reception to such resources; although some are taking advantage of mediated search services or doing their own searching of vendor-supplied, locally loaded, or CDROM databases, others are reluctant to use them. Among the factors identified as contributing to faculty use (or lack of use) are the content of the databases, the ease of end-user systems, the availability of computers, and faculty characteristics such as discipline-affiliation or age.
While reluctance was to be expected when databases first became widely available, it seemed likely that, over time, either growing familiarity with the technology, the development of electronic sources in all disciplines, or better interfaces would lead to greater acceptance. The research, however, has not shown a clear trend toward progressively greater use; instead, the results are mixed. ${ }^{1-4}$ Further studies testing disciplinary affiliation as one likely explanation for the uneven pattern of use yielded mixed results regarding use by faculty in the sciences and

Joan B. Fiscella is Bibliographer for Professional Studies in the Collections Development Department at the University of Illinois at Chicago (UIC) Library, P.O. Box 8198, M/C234, Chicago, IL 60680. Edward Proctor is Assistant Reference Librarian in the Reference Department at the UIC Library.The authors would like to thank Marta Kuszczak, now Government Documents and Maps Reference Bibliographer at Dartmouth College, for her participation in the SPIRES/ERIC task force and survey of the faculty. We designed the survey questionnaire with assistance from Timothy Johnson of the University Office of Survey Research, a consulting service available to UIC faculty upon request; we also wish to thank him for his help with statistics. In addition, we would like to thank our colleagues Ann Weller and Stephen Wiberley for their helpful comments and suggestions about the paper, Nancy John for historical information, and Nancy Sack for reviewing the tables. 
the humanities. ${ }^{5,6}$ Because high costs may deter use, many libraries began licensing databases for patrons to use without charge. Yet the ready availability of locally loaded or no-cost commercial systems has not necessarily prompted frequent enduser searching by faculty. ${ }^{7.8}$

Since the late 1970 s better system designs and more extensive training have been proposed as ways to encourage faculty to use electronic systems. ${ }^{9-11}$ Studies testing the efficacy of front-ends have begun. For instance, Michael Sullivan, Christine Borgman, and Dorothy Wippern compared the performance of doctoral students using a command-driven system with those using a menu system. ${ }^{12}$ They found that, although those who used the menu-driven approach interacted less with the system than did those who used the command mode, both groups did equally well in measures of performance.

The availability of two software interfaces for the Educational Resources Information Center (ERIC) database at the University of Illinois at Chicago (UIC) provided an unusual opportunity to examine faculty use of this locally loaded resource and faculty response to the two front-ends. A study of faculty responses to the databases could serve as a baseline against which to measure change in the rate of use and level of satisfaction. A comparison of faculty preferences for one or the other interface would suggest which features were most important to them and serve as a guide to choosing interfaces for other databases. Related questions could be addressed. Do faculty in some disciplines use locally loaded databases more than those in others? Are there any identifiable characteristics common to those who frequently search electronic databases, as compared to those who do not? Are those who search a single database, in this case ERIC, also likely to look at other bibliographic databases?

In this paper the authors show the results of using a survey instrument to gather data on faculty preferences for one or the other software and to assess their use of the locally loaded ERIC databases. We will outline the differences in the two database interfaces and report on faculty use of ERIC, and their preference for, or satisfaction with, one or the other interface for the locally loaded databases. We will also outline the use of other databases by this same group of faculty.

\section{SPIRES/ERIC and BRS/ERIC}

Since 1987, the UIC Library had been looking for ways to provide article citation databases via the mainframe and the campus network in order to avoid extensive investment in CD-ROM technology. Because the campus Computer Center had mounted on the mainframe Stanford's SPIRES database manager with the

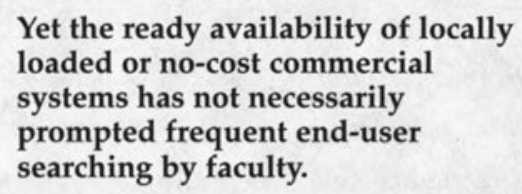

Prism interface, the library was able to use loaders that Syracuse University had developed for ERIC and was distributing to SPIRES users. Only a small financial investment was needed for the ERIC data. During this time, the University of Illinois Central Administration decided to fund the acquisition of BRS for the libraries. BRS' OnSite program used ready-toload data, and the libraries chose ERIC (because of its high use and relatively low cost), H.W. Wilson Company databases, and Current Contents. Because long-term funding for BRS by the university was not assured, the UIC Library administration chose to continue to support the SPIRES version of ERIC as well.

Both ERIC databases are searchable on terminals in all library sites, on networked campus computers, or by remote access using office or home personal computers by faculty, staff, and students with 
campus computer-Academic Data Network (ADN)-accounts. Both were announced through notes in campus newspapers, in newsletters sent to faculty, in orientation and instruction sessions, and through activities in celebration of the remodeling of the Main Library.

Thus the UIC Library has made available to its users two ERIC databases, loaded on different computers and run with different software. The SPIRES/ Prism ERIC database became available in late summer 1991; the BRS version in
October of the same year. That both databases became available within three months of each other was a result of the timing of development activities: writing the help screens and user documentation for the databases, customizing the MENTOR interface for the BRS software, and loading the databases on the campus computer (SPIRES/Prism version) and the university computer (BRS version). For purposes of this paper, the former version of ERIC will be called SPIRES/ERIC; the latter, BRS/ERIC.

\section{TABLE 1}

\section{Comparison of Selected Features of SPIRES/ERIC and BRS/ERIC}

\begin{tabular}{|c|c|c|}
\hline Feature & SPIRES/ERIC & BRS/ERIC \\
\hline \multicolumn{3}{|l|}{ Searching } \\
\hline Keyword & Specified field only & $\begin{array}{l}\text { In any field; use of } \\
\text { suffix delimiters }\end{array}$ \\
\hline Refining searches & Default: AND, within field & Default: WITH \\
\hline Word adjacency & Not available & Available \\
\hline Descriptors/Identifiers & Keyword & Indexed phrases \\
\hline
\end{tabular}

\section{Displaying}

Record format

Screen format

\section{Select fields}

\section{Manipulating Results}

Review search history

Combine sets

Sort/Print/Electronic

Transfer

\section{Access}

Library menu

Lib. terminals/Campus computers/Dial-in
Brief/Full

Up to 16 single lines, date and title/brief

Single record/full

In customized "report" format
Short/Medium/Long

No more than a single record per screen

User selected fields

Available

AND, OR, NOT with any available sets

Available

$$
\begin{aligned}
& \text { Not available } \\
& \text { AND, OR, NOT with } \\
& \text { current set }
\end{aligned}
$$

Available

\author{
Available
}




\section{Comparison of Interfaces}

The two interfaces differ in ways of searching the database and in displaying and manipulating the results, as indicated in table 1. Two examples illustrate the difference in practice: the protocols available to limit search results and the types of display of retrieved citations. SPIRES/ ERIC helps the searcher limit results by requiring the designation of fields to be searched (e.g., title or author). BRS/ERIC, conversely, aids precise searching by allowing word adjacency (e.g., new adj math), descriptor or identifier phrases (instead of individual words), and key words within a field by suffixes (e.g., multicultural.ti.). Using BRS/ERIC, the searcher has more flexibility in searching and altering a search in progress.

The displays differ as well (see figure 1). The SPIRES/ERIC brief display format yields a list of dates and titles, useful for browsing titles. In contrast, the briefest BRS/ERIC format is the short citation, including major descriptors, one citation to a screen. Thus, SPIRES/ERIC builds in a constraint potentially useful to beginning searchers, and it provides title browsing lists. In contrast, BRS/ERIC offers more options (and thus flexibility) for the user to modify the search request as needed.

Both interfaces offer consistency among related databases. The SPIRES/ERIC interface is similar to other applications of SPIRES/Prism, such as resumes or local information databases, available to campus users. In aid of this consistency, no reprogramming was possible for types of search parameters, like title or author, nor search screen displays. In contrast, the BRS
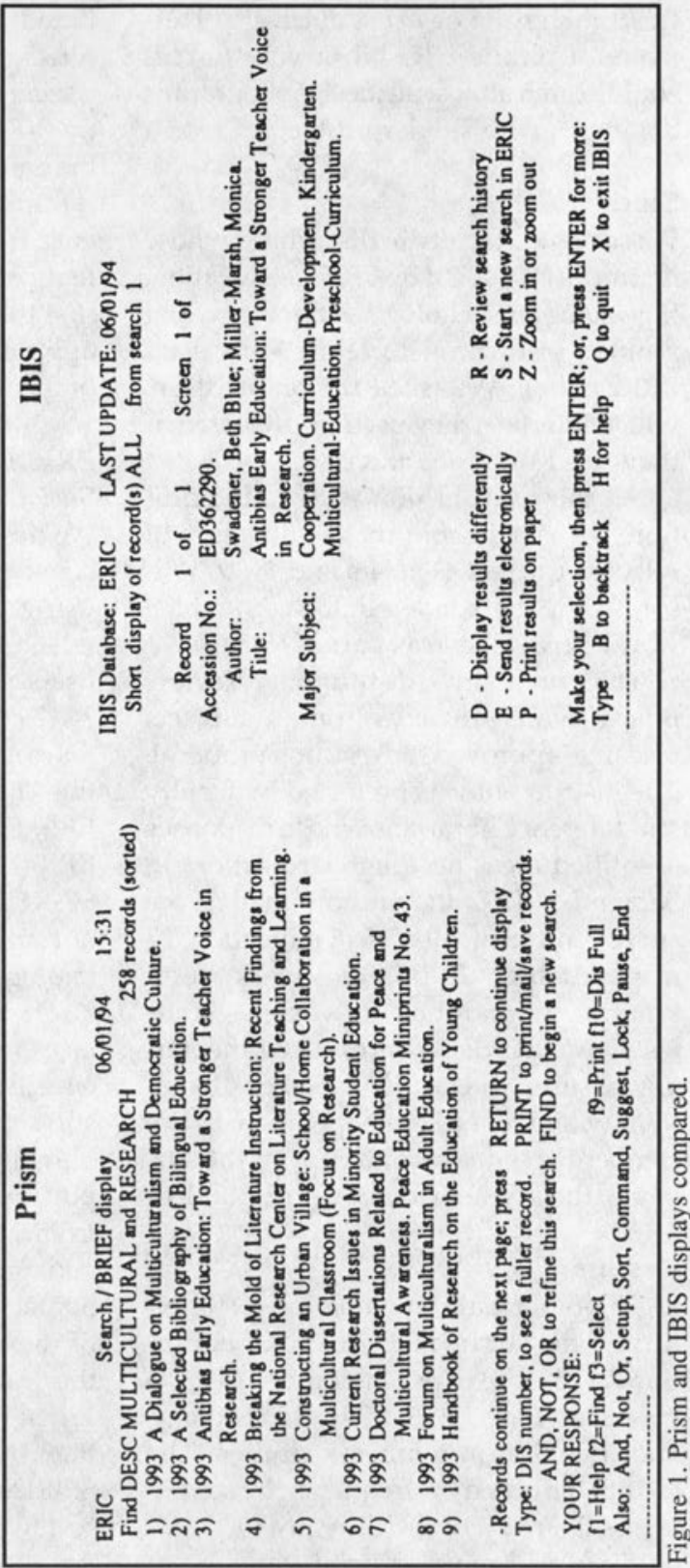

MENTOR interface customized by UIC librarians provided a level of consistency among the selected databases, grouped under the name IBIS (Illinois Bibliographic Information Service), and some similarity with the functions of the NOTIS/ 
LUIS online catalog in use at UIC. ${ }^{13,14}$ Thus users of online UIC Library resources could search almost all local bibliographic databases with similar protocols.

\section{Study}

We surveyed faculty in disciplines whose literature is covered by ERIC - education, kinesiology, psychology, social work, and women's studies - to learn who used ERIC online. We asked the online users which interface they used or preferred; if they used only one interface, we asked about their satisfaction with it. In addition, we asked about the faculty's use of selected Current Contents and H.W. Wilson Company's index databases, which were also available as part of IBIS.

The university's Institutional Review Board, which reviews human subjects research, approved the research proposal. The instrument was pretested by faculty and reference librarians whose responses identified areas needing clarification. In September 1992 the authors mailed the survey to 148 faculty: 65 in education, 37 in psychology, 30 in social work, 16 in kinesiology, and three in women's studies. Our cover letter introduced the survey, assured the faculty member of anonymity, and requested cooperation. In December we sent a second copy of the survey to those who had not yet responded.

\section{Results}

Eighty-one faculty members $(54.7 \%)$ returned the survey: $30(46.1 \%)$ in education, $22(59.4 \%)$ in psychology, 17 (56.6\%) in social work, $9(56.2 \%)$ in kinesiology, and $3(100 \%)$ in women's studies. The faculty indicated the frequency, by semester, of their use of ERIC in any form, including electronic or print versions of Current Index to Journals in Education (CIJE) or Research in Education (RIE). No statistically significant difference was found among the departments; nor was any significant difference in frequency of use found when comparing the education faculty with all other disciplines com- bined. Furthermore, no statistically significant difference was found when comparing the use of each form of ERIC (CIJE or RIE in print, locally loaded ERIC, librarian-mediated search, or CD-ROM) by discipline. The lack of significant differences for both frequency and form of use lent credence to the original assumption that the selected disciplines would be an appropriate population to test for the use of the electronic versions of ERIC.

\section{ERIC Online: Use, Preference, and Satisfaction}

We designed one set of questions to discover the extent to which faculty were using the online ERIC resources and which of the two ERIC interfaces faculty users preferred. Of the 81 respondents, $24(29.6 \%)$ said they had used ERIC online; of these 24 , only seven $(29.2 \%)$ said they had used both SPIRES/ERIC and BRS/ERIC, nine (37.5\%) had used only BRS/ERIC, one $(4.2 \%)$ had used only SPIRES/ERIC, and seven $(29.2 \%)$ were not sure which of the two interfaces they had used.

The seven who had used both interfaces were asked to indicate their preference by interface function (author and subject searching, combining sets, displaying and sorting results, creating reports, printing, and sending results electronically, as well as overall ease of use), and for getting in and out of the database. Six faculty responded, and the majority of these expressed no preference for either interface, for any of the functions. When respondents indicated preference, they tended to choose BRS/ERIC over SPIRES/ERIC for most functions. Because so few respondents indicated they had used both versions of ERIC, we cannot draw any conclusions applicable to a larger population.

Respondents who had used one or the other ERIC database (but not both) were asked for their satisfaction level with the interface functions. Seventeen faculty provided usable responses; nine had used 
BRS/ERIC, one had used SPIRES/ERIC, and seven were unsure which program they had used. Table 2 shows the comparison of satisfaction by interface. We combined "very satisfied" and "fairly satisfied" responses into "satisfied" and combined "not very satisfied" and "not at all satisfied" into "not satisfied."

TABLE 2

\section{Comparison of Satisfaction Ratings, Including Non-Use, for System Functions, by Interface, $\mathrm{N}=17$}

\begin{tabular}{|c|c|c|c|c|c|c|c|c|}
\hline \multirow{3}{*}{$\begin{array}{l}\text { Function } \\
\text { Author searching }\end{array}$} & \multirow{3}{*}{$\begin{array}{l}\text { Interface } \\
\text { BRS/ERIC }\end{array}$} & \multicolumn{5}{|c|}{ Satisfaction Ratings } & \multirow[b]{2}{*}{ No } & \multirow[b]{2}{*}{ Answe } \\
\hline & & Satisfied & \multicolumn{2}{|c|}{ Not Satisfied } & \multicolumn{2}{|c|}{ Never Used } & & \\
\hline & & $777.8 \%$ & 1 & $11.1 \%$ & 0 & 0 & 1 & $11.1 \%$ \\
\hline & SPIRES/ERIC & 1100.0 & 0 & 0 & 0 & 0 & 0 & 0 \\
\hline & System-unknown & $\begin{array}{ll}6 & 85.7\end{array}$ & 0 & 0 & 1 & 14.3 & 0 & 0 \\
\hline \multirow[t]{3}{*}{ Subject searching } & BRS/ERIC & $5 \quad 55.6$ & 3 & 33.3 & 0 & 0 & 1 & 11.1 \\
\hline & SPIRES/ERIC & 1100.0 & 0 & 0 & 0 & 0 & 0 & 0 \\
\hline & System-unknown & $\begin{array}{ll}6 & 85.7\end{array}$ & 1 & 14.3 & 0 & 0 & 0 & 0 \\
\hline \multirow[t]{3}{*}{ Combining sets } & BRS/ERIC & $5 \quad 55.6$ & 2 & 22.2 & 1 & 11.1 & 1 & 11.1 \\
\hline & SPIRES/ERIC & 1100.0 & 0 & 0 & 0 & 0 & 0 & 0 \\
\hline & System-unknown & $\begin{array}{ll}4 & 57.1\end{array}$ & 0 & 0 & 3 & 42.9 & 0 & 0 \\
\hline \multirow[t]{3}{*}{ Displaying results } & BRS/ERIC & $\begin{array}{ll}7 & 77.8\end{array}$ & 1 & 11.1 & 0 & 0 & 1 & 11.1 \\
\hline & SPIRES/ERIC & 1100.0 & 0 & 0 & 0 & 0 & 0 & 0 \\
\hline & System-unknown & $\begin{array}{ll}5 & 71.4\end{array}$ & 2 & 28.6 & 0 & 0 & 0 & 0 \\
\hline \multirow[t]{3}{*}{ Sorting results } & BRS/ERIC & 333.3 & 1 & 11.1 & 4 & 44.4 & 1 & 11.1 \\
\hline & SPIRES/ERIC & 1100.0 & 0 & 0 & 0 & 0 & 0 & 0 \\
\hline & System-unknown & 228.6 & 1 & 14.3 & 4 & 57.1 & 0 & 0 \\
\hline \multirow[t]{3}{*}{ Creating reports } & BRS/ERIC & 22.2 & 0 & 0 & 6 & 66.7 & 1 & 11.1 \\
\hline & SPIRES/ERIC & 0 & 1 & 100.0 & 0 & 0 & 0 & 0 \\
\hline & System-unknown & $2 \quad 28.6$ & 1 & 14.3 & 4 & 57.1 & 0 & 0 \\
\hline \multirow[t]{3}{*}{ Printing } & BRS/ERIC & $\begin{array}{ll}6 & 66.7\end{array}$ & 0 & 0 & 2 & 22.2 & 1 & 11.1 \\
\hline & SPIRES/ERIC & 1100.0 & 0 & 0 & 0 & 0 & 0 & 0 \\
\hline & System-unknown & $\begin{array}{ll}5 & 71.4\end{array}$ & 0 & 0 & 2 & 28.6 & 0 & 0 \\
\hline \multirow{3}{*}{$\begin{array}{l}\text { Sending results } \\
\text { electronically }\end{array}$} & BRS/ERIC & 222.2 & 0 & 0 & 4 & 44.4 & 3 & 33.3 \\
\hline & SPIRES/ERIC & 1100.0 & 0 & 0 & 0 & 0 & 0 & 0 \\
\hline & System-unknown & $\begin{array}{ll}0 & 0\end{array}$ & 2 & 28.6 & 5 & 71.4 & 0 & 0 \\
\hline \multirow[t]{3}{*}{ Ease of use } & BRS/ERIC & $\begin{array}{ll}7 & 77.8\end{array}$ & 1 & 11.1 & & N.A. & 1 & 11.1 \\
\hline & SPIRES/ERIC & 1100.0 & 0 & 0 & & N.A. & 0 & 0 \\
\hline & System-unknown & $\begin{array}{ll}5 & 71.4\end{array}$ & 2 & 28.6 & & N.A. & 0 & 0 \\
\hline \multirow[t]{3}{*}{ Getting in } & BRS/ERIC & $\begin{array}{ll}6 & 66.7\end{array}$ & 2 & 22.2 & & N.A. & 1 & 11.1 \\
\hline & SPIRES/ERIC & 1100.0 & 0 & 0 & & N.A. & 0 & 0 \\
\hline & System-unknown & $\begin{array}{ll}6 & 85.7\end{array}$ & 1 & 14.3 & & N.A. & 0 & 0 \\
\hline \multirow[t]{3}{*}{ Getting out } & BRS/ERIC & $5 \quad 55.6$ & 3 & 33.3 & & N.A. & 1 & 11.1 \\
\hline & SPIRES/ERIC & 1100.0 & 0 & 0 & & N.A. & 0 & 0 \\
\hline & System-unknown & $\begin{array}{ll}5 & 71.4\end{array}$ & 2 & 28.6 & & N.A. & 0 & 0 \\
\hline
\end{tabular}


The majority of respondents who had used each function were satisfied with the function. The one respondent who reported using SPIRES/ERIC indicated satisfaction with all functions except for "reporting." One respondent using BRS/ ERIC answered none of the questions about its functions. Of the remaining BRS/ERIC respondents, more indicated satisfaction than dissatisfaction with all functions used. Three respondents indicated they were not satisfied with subject searching, and three were dissatisfied with the method of exiting the BRS/ERIC database. Of the respondents who did not know which of the two interfaces they had used, most also indicated satisfaction with the functions they had used, except for sending the results electronically.

Table 2 shows that a number of these faculty made no use of several available functions, in contrast with the faculty who used both interfaces. Although the reporting-SPIRES/ERIC user was familiar with all functions listed, BRS/ERIC or system-unknown reporters indicated that they had never used the functions of creating reports (10), electronically sending results (9), sorting results (8), combining sets (4), or printing results (4). Searching by author or subject and displaying the results appear to be basic functions.

For further analysis, all 81 respondents were divided into two subgroups according to whether or not they had used University of Illinois locally loaded ERIC. The first subgroup consisted of 24 faculty who had used locally loaded ERIC; the second consisted of the remaining 57 faculty, including those who did not answer the question, as well as those who responded that they had not used locally loaded ERIC. Data were compared using the demographic factors of discipline affiliation, number of years at UIC, rank, age, and gender. Because personal computers or terminals are not uniformly available on campus, we also compared data for points of access to campus computing systems.

Comparing the two subgroups by disciplinary affiliation, the faculty of education were evenly divided between those who used and those who did not report using the local ERIC; in each of the other disciplines, fewer than 25 percent of the faculty reported using the local ERIC. Of

TABLE 3

Comparison of the Users and Nonusers of Locally Loaded ERIC by Discipline and by Academic Rank, $\mathrm{N}=81$

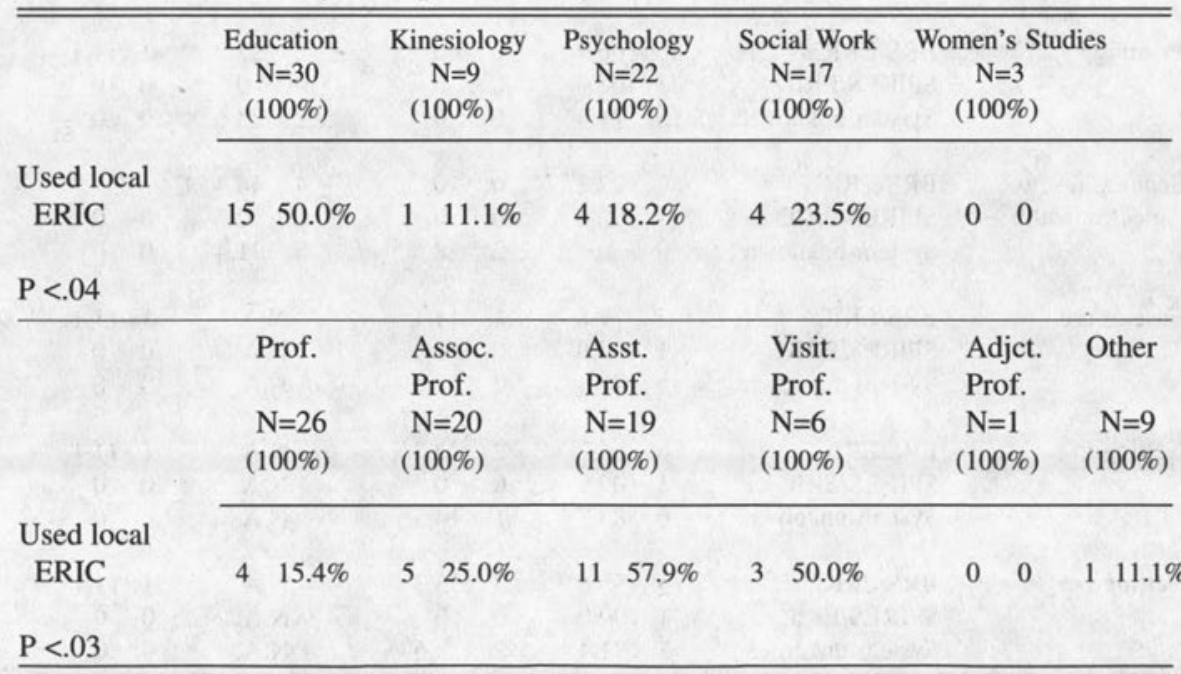


TABLE 4

\section{Comparison of the Users and Non-users of Locally Loaded ERIC by Access to ADN, $\mathbf{N}=\mathbf{8 1}$}

\begin{tabular}{|c|c|c|c|c|c|}
\hline & & \multicolumn{3}{|c|}{ ADN Point of Access } & \multirow[b]{2}{*}{$\begin{array}{l}\text { home } \\
\mathrm{N}=65\end{array}$} \\
\hline & $\begin{array}{l}\text { have } \\
\text { ADN acct.* } \\
\mathrm{N}=79\end{array}$ & $\begin{array}{l}\text { office } \\
N=71\end{array}$ & $\begin{array}{l}\text { dept. } \\
\mathrm{N}=67\end{array}$ & $\begin{array}{l}\text { unit/bldg. } \\
\mathrm{N}=65\end{array}$ & \\
\hline Used local ERIC & $\begin{array}{l}18 / 24 \\
75.0 \%\end{array}$ & $\begin{array}{l}11 / 21 \\
52.4 \%\end{array}$ & $\begin{array}{l}16 / 22 \\
72.7 \%\end{array}$ & $\begin{array}{l}12 / 18 \\
66.7 \%\end{array}$ & $\begin{array}{l}8 / 20 \\
40.0 \%\end{array}$ \\
\hline $\begin{array}{l}\text { Did not use } \\
\text { local ERIC }\end{array}$ & $\begin{array}{l}26 / 55 \\
47.3 \%\end{array}$ & $\begin{array}{l}25 / 50 \\
50.0 \%\end{array}$ & $\begin{array}{l}31 / 45 \\
68.9 \%\end{array}$ & $\begin{array}{l}30 / 47 \\
63.8 \%\end{array}$ & $\begin{array}{l}13 / 45 \\
28.9 \%\end{array}$ \\
\hline $\begin{array}{l}* \mathrm{P}<.06 \\
\text { (Numerators refer to } \\
\text { numbers answering }\end{array}$ & $\begin{array}{l}\text { bers of respo } \\
\text { uestions, am }\end{array}$ & $\begin{array}{l}\text { s answeri } \\
\text { e respond }\end{array}$ & $\begin{array}{l}\text { N questic } \\
\text { sing or } n\end{array}$ & $\begin{array}{l}\text { enominators } \\
\text { g locally lo }\end{array}$ & $\begin{array}{l}\text { to } \\
\text { ERIC.) }\end{array}$ \\
\hline
\end{tabular}

the remaining demographic factors, only rank showed a statistically significant difference ( $\mathrm{p}=<.03$, Pearson's). (See table 3.) Eleven (57.9\%) assistant professors, and three $(50.0 \%)$ visiting professors had used the locally-loaded ERIC, while 26 percent or fewer of the other ranks had done so. Although the higher percentage of assistant professors would indicate that relatively younger faculty used the local ERIC more frequently than did older faculty, the comparison of the two subgroups by age in five-year ranges showed no statistical significance. However, in the faculty group aged $\leq 34$ years and in the group aged 35-39 years, there was a $50 \%-50 \%$ split between those who used the locally loaded ERIC and those who did not indicate use. In all other age ranges, over 60 percent did not use the local ERIC.

Campus computer accounts for the Academic Data Network (ADN) are available for the asking, at no fee, to all campus-affiliated faculty, students, and staff. The survey asked faculty to indicate whether or not they had an ADN account and in what locations they had access to computer connections. Forty-four (55.7\%) of the 79 respondents indicated that they had ADN accounts. Faculty were more likely to have access points in the department $(70.1 \%$ of 67 respondents) or in the building $(64.6 \%$ of 65$)$ than in their offices $(50.7 \%$ of 75$)$ or at home $(32.3 \%$ of 65$)$. Between seven percent and 21 percent, however, indicated that they did not know if they had access to the ADN in any of the three workplace areas or at home.

A significantly greater percent of users of the local ERIC had ADN accounts than did nonusers of local ERIC (see table 4). On the other hand, there was no significant association between points of access and use of local ERIC. In other words, whether or not the faculty had ADN access in their office, department, building, or home was not associated with whether or not they used locally loaded ERIC; in fact, over 50 percent or more of the respondents in the group who did not use local ERIC answered affirmatively for all workplace points of access.

\section{Use of Other Local Online Databases}

The survey queried the faculty on their use of other indexes and abstracts in a 
TABLE 5

Faculty Use of Indexes and Abstracts by Format*

\begin{tabular}{|c|c|c|c|c|c|c|c|c|}
\hline \multirow{3}{*}{$\begin{array}{l}\text { Index } \\
\text { Psychol. Abstracts } \\
\text { (N=66) }\end{array}$} & \multicolumn{6}{|c|}{ Formats } & \multirow{2}{*}{\multicolumn{2}{|c|}{$\begin{array}{l}\text { Through } \\
\text { librarian }\end{array}$}} \\
\hline & & \multicolumn{2}{|c|}{ CD-ROM } & \multicolumn{2}{|c|}{$\begin{array}{l}\text { Own search } \\
\text { on computer }\end{array}$} & & \\
\hline & 22 & $33.3 \%$ & 12 & $18.2 \%$ & 12 & $18.2 \%$ & 9 & $13.6 \%$ \\
\hline $\begin{array}{l}\text { Soc. \& Behav. Curr. Cont. } \\
\qquad(\mathrm{N}=65)\end{array}$ & 28 & 43.1 & 2 & 3.1 & 15 & 23.1 & 5 & 7.7 \\
\hline $\begin{array}{l}\text { Soc. Sci. Cit. Index } \\
\qquad(\mathrm{N}=63)\end{array}$ & 29 & 46.0 & 4 & 6.3 & 7 & 11.1 & 3 & 4.8 \\
\hline $\begin{array}{l}\text { Arts \& Hum. Curr. Cont. } \\
\qquad(\mathrm{N}=53)\end{array}$ & 4 & 7.5 & 0 & 0 & 5 & 9.4 & 1 & 1.9 \\
\hline $\begin{array}{l}\text { Life Sci. Curr. Cont. } \\
\qquad(\mathrm{N}=52)\end{array}$ & 8 & 15.4 & 1 & 1.9 & 2 & 3.8 & 0 & 0 \\
\hline $\begin{array}{l}\text { Soc. Sci. Index } \\
\qquad(\mathrm{N}=49)\end{array}$ & 5 & 10.2 & 1 & 2.0 & 8 & 16.3 & 3 & 6.1 \\
\hline $\begin{array}{l}\text { Reader's Guide } \\
\qquad(\mathrm{N}=48)\end{array}$ & 8 & 16.7 & 1 & 2.1 & 2 & 4.2 & 0 & 0 \\
\hline $\begin{array}{l}\text { Humanities Index } \\
\qquad(\mathrm{N}=47)\end{array}$ & 2 & 4.3 & 1 & 2.1 & 4 & 8.5 & 0 & 0 \\
\hline
\end{tabular}

variety of formats over the previous two years. The results are shown in table 5 . Not unexpectedly, faculty used Psychological Abstracts ${ }^{\oplus}$, Current Contents: Social $\mathcal{E}$ Behavioral Sciences, and the Social Sciences Citation Index to the greatest extent. Most used the paper format or their own computer, and relatively few had librarians perform searches for them. PsycLIT ${ }^{*}$ (CD-ROM format) has been available at single workstations in UIC's Library of the Health Sciences since February 1992, but none of the other titles were available in CD-ROM version at UIC. Because the tape version of Psychological Abstracts ${ }^{\circledast}$,
$P_{s y c I N F O}{ }^{\circledR}$, was not mounted as part of IBIS until October 1993, and because the Institute for Scientific Information (ISI ${ }^{\otimes}$ ) citation databases were not available locally, it seemed obvious that some faculty were finding other end-user searching avenues to reach the databases. This was confirmed for 34 faculty (41.9\%) who indicated that they used other academic and public libraries to search indexes or online databases.

Finally, similar to findings about ERIC, the relationship between having an $\mathrm{ADN}$ account and personally searching databases other than ERIC is suggestive, as 
shown in table 6. Among the population of those who did their own searching on computer for the indexes and abstracts other than ERIC (a range of two to fifteen, depending on index) the comparison of those who either had, did not have, or did not know if they had an ADN account, showed statistically significant differences for Current Contents: Social and Behavioral Sciences, Social Sciences Index, and for Psychological Abstracts.

\section{Conclusions}

Assessing faculty response to online databases by survey provided interesting data on system use and design. The method, however, had its flaws, because of a self-selection bias among those who elected to answer the survey, the relatively low response rate $(54.7 \%)$, and the apparent low recollection of the databases among the respondents. Low recollection was suggested by the number reporting their ignorance of which system they used, although Christine L. Borgman, Donald O. Case, and Dorothy Ingebretsen also reported faculty confusion over database and vendor names. ${ }^{15}$ Our survey questions were framed using the terms "IBIS" and "SPIRES/Prism." At the time, to reach BRS/ERIC, one first had to choose the IBIS entry from the Library Menu (see figure 2) or type "IBIS" from within one's computer account. The searchers then had to proceed through five more screens before beginning a search, unless they typed the file name at the third screen. In contrast, choosing the Library Menu entry "ERIC" brought up SPIRES/ERIC. Its opening screen identified the (SPIRES) Prism software. Those respondents who were unable to identify which interface they used may have answered the questionnaire without reviewing the ERIC database they had used or may have forgotten the interface name.

Another factor related to access may also have contributed to the difficulty in comparing the two software interfaces. In

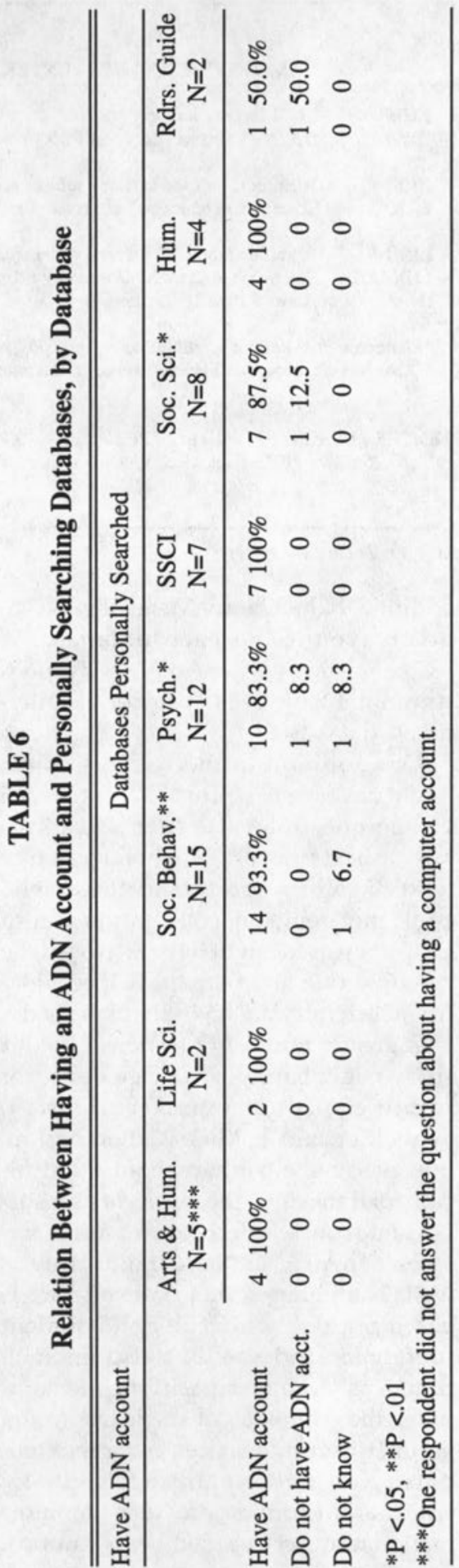


LIBRARY

\section{MOVE CURSOR, USE <ENTER>}

\section{LUIS - UIC Library catalog}

ILLINET - ILLINET Online (LCS and FBR)

\section{IBIS - Periodical indexes in many subject areas \\ ERIC - Literanure in education and related areas}

LIBINF - A guide to the UIC Library systems and services

LIBMAII - Electronic mail to the University Library

Hours - Hours for the UIC Libraries

-Electronic Publications (submenu

-Other - Access to other libraries' systems (submenu

\section{ENTER $=$ Execute $\mathrm{PF} 1=$ Help $\quad \mathrm{PF} 2=$ Top $\quad \mathrm{PF} 3=\mathrm{QUTT} \quad \mathrm{PF5}=$ Locate PF6 $=$ Retrieve PF7 = Backward PF8 = Forward PF12= Cancel \\ $\Longrightarrow$}

Figure 2. Library menu.

addition to the Library Menu, there were other avenues to each database. A searcher using only one of these avenues would not have been aware of the alternative database.

One solution to the recall problem might have been to provide aids to recall on the questionnaire, such as sample screen illustrations. ${ }^{16}$ Telephoning faculty who did not respond and those who could not remember which version of ERIC they used might have increased the response rate and perhaps helped identify which interface an individual used. ${ }^{17}$

A greater number of responses to this study might have provided guidance for future choices of interfaces. Doris J. Schlichter and J. Michael Pemberton, however, have warned about the difficulty of translating the results of user surveys into concrete decisions for future services. ${ }^{18}$ There is another kind of issue as well. The library's choice of software is based not only on faculty and student preference and use, but also on such things as storage capacity of the computer, the economics of single institution vs. interinstitutional licenses, or the complexity of multiple arrangements by which an institution provides the information resources needed by its campus.
In other words, even unflawed user studies are only one factor in deciding appropriate software for online resources.

Despite the limitations and caveats, this survey did provide a case study of use of two different software interfaces for the same locally loaded database content. A year after the databases became available, the few faculty showing a preference for one or the other chose the customized BRS MENTOR interface used in IBIS/ERIC over the SPIRES/ERIC interface for most functions. Most faculty had no preference, suggesting that their retrieval results were more important than the system used or that the differences were not significant.

Among the respondents who had used only one or the other interface or did not know which interface they had used, the satisfaction rating in overall ease of use apparently did not depend on the number of features they had used. The survey results suggest a general hierarchy or cluster of user approaches to bibliographic databases, with the functions of author or subject searching and displaying most crucial. The data do not indicate whether these patterns are based on users' bibliographic or information needs, on the convenience of the software or the hardware systems, or on the users' skills. Because the respondents who used both interfaces reported using all functions, it is likely that user's skill levels account for not using some of the functions, in which case instruction may, over time, change the patterns.

The survey also provided data on characteristics of faculty who used electronic online systems by comparing faculty who 
had used the locally loaded ERIC with those who had not. Although Jan Horner and David Thirlwall found variation across disciplines regarding any kind of use of machine-readable databases, they found less variation among all disciplines for end-user searching. ${ }^{19}$ We did not find significant differences among disciplines studied. Although only academic rank showed statistical significance, analysis of rank and age pointed to a greater use of the locally loaded ERIC among younger faculty in beginning ranks. More important, perhaps, were the findings which associated having a campus computer account (ADN) with use of the locally loaded ERIC and with use of the locally loaded Current Contents: Social and Behavioral Sciences and H.W. Wilson's Social Sciences Index.

Because computer connections through terminals or personal computers are not uniformly accessible in offices or buildings across the UIC campus, we expected to find place of access significantly associated with the use of locally loaded databases. Other studies have shown inconsistent results about whether the availability of computers or terminals contributes to faculty searching online databases. ${ }^{20-22}$ Our own study did not show any statistically significant association between place of access and the use of the locally loaded databases. Thus use of these databases may simply be a function of scholars' time and patience in learning the systems, as suggested by Stephen Lehmann and Patricia Renfro. ${ }^{23}$ Demographic analysis suggests a direction for change: since the faculty who are using online resources are at the beginning stages of their academic careers, it is likely that they have learned to use online databases as students and continue to use them in spite of some inconvenience in learning new systems.

Taken together, the findings concerning rank, age, and ADN accounts recommend a strategy for promoting local online resources and helping faculty to take advantage of the power and potential convenience afforded them. If remote use of online resources depends on campus computer connectivity, librarians who are involved with new faculty orientations could encourage faculty to acquire the necessary computer accounts for remote use of library resources. Working cooperatively with the computing center, the library could issue accounts, thus increasing convenience of access for faculty, as well as students and staff.

This study suggests that there is a range of faculty use of local online resources across departments. On the one hand, there has not been an immediate adoption of the online sources of even those indexes and abstracts that are used in print forms; many faculty continue to

\section{It is likely that many faculty will continue to do at least some of their work in ways similar to those that they are using currently.}

use print resources as they have in the past. Further study would be necessary to determine whether intensive promotion of the resources would increase use. On the other hand, as increasing numbers of newly hired faculty are likely to have used online resources as students, we may expect to see both a greater use of databases and a wider range of databases used in the future.

Still, since not all information needs are met through these resources, it is likely that many faculty will continue to do at least some of their work in ways similar to those that they are using currently. This could mean using citations in known references to find new information sources, as Harriet Lönnqvist's study suggests is characteristic of mature scholars, or using resources of other institutions. ${ }^{24}$ The more complex question is to what extent libraries can afford to commit resources to both print access services and to electronic resources and for how long a time. 


\section{Notes}

1. Alan E. Bayer and Gerald Jahoda, "Effects of Online Bibliographic Searching on Scientists' Information Style," Online Review 5, no. 4 (Aug. 1981): 323-33.

2. Christine L. Borgman, Donald O. Case, and Dorothy Ingebretsen, "University Faculty Use of Computerized Databases: An Assessment of Needs and Resources," Online Review 9, no. 4 (1985): 307-32.

3. Ann B. Hubble, "MEDLINE Access Through an Online Catalog: A Study of User Reactions," in American Society of Information Science Proceedings (Medford, N.J.: Learned Information, 1988), 137-42.

4. Beryl Glitz, "Testing the New Technology: MEDLINE on CD-ROM in an Academic Health Sciences Library," Special Libraries 79, no. 1 (winter 1988): 28-33.

5. Jan Horner and David Thirlwall, "Online Searching and the University Researcher," Journal of Academic Librarianship 14, no. 4 (1988): 225-30.

6. Stephen E. Wiberley Jr. and William G. Jones, "Patterns of Information Seeking in the Humanities," College \& Research Libraries 50, no. 6 (Nov. 1989): 638-45.

7. Richard W. Meyer, "Management, Cost, and Behavioral Issues with Locally Mounted Databases," Information Technology and Libraries (Sept. 1990): 226-41.

8. Karen L. Curtis, Ann C. Weller, and Julie M. Hurd, "Information Seeking Behavior: A Survey of Health Sciences Faculty Use of Indexes and Databases," Bulletin of the Medical Library Association 81, no. 4 (Oct. 1993): 383-92.

9. Charles T. Meadow, “ONLINE Searching and Computer Programming: Some Behavioral Similarities (Or ... Why End Users Will Eventually Take Over the Terminal)," Online 3, no. 1 (Jan. 1979): 49-52.

10. William H. Mischo and Jounghyoun Lee, "End-User Searching of Bibliographic Databases," Annual Review of Information Science and Technology (ARIST) 22 (1987): 227-63.

11. Susan Siegfried, Marcia J. Bates, and Deborah N. Wilde, "A Profile of End-User Searching Behavior by Humanities Scholars: The Getty Online Searching Project Report No. 2," Journal of the American Society for Information Science 44, no. 5 (1993): 273-91.

12. Michael V. Sullivan, Christine L. Borgman, and Dorothy Wippern, "End-Users, Mediated Searches, and Front-End Assistance Programs on DIALOG: A Comparison of Learning, Performance, and Satisfaction," Journal of the American Society for Information Science 41, no. 1 (Jan. 1990): $27-42$.

13. See Dennis A. Norlin et al., "Interface Design and Development: The Human Factor," Library Hi Tech 10, no. 3 (1992): 7-24, for discussion of developing a microcomputer interface for BRS MENTOR.

14. IBIS was a joint project of the Libraries of the University of Illinois at Urbana-Champaign and the University of Illinois at Chicago. 313.

15. Borgman, Case, and Ingebretsen, "University Faculty Use of Computerized Databases,"

16. Seymour Sudman and Norman M. Bradburn, Response Effects in Surveys: A Review and Synthesis (Chicago: Aldine Publishing Co., 1974).

17. Don A. Dillman, Mail and Telephone Surveys: The Total Design Method (New York: John Wiley \& Sons, 1978), 191.

18. Doris J. Schlichter and J. Michael Pemberton, "The Emperor's New Clothes? Problems of the User Survey as a Planning Tool in Academic Libraries," College \& Research Libraries 53, no. 3 (May 1992): 257-65.

19. Horner and Thirlwall, "Online Searching," 227.

20. Katharine E. Clark and Joni Gomez, "Faculty Use of Databases at Texas A\&M University," RQ 30, no. 2 (winter 1990): 241-48.

21. Julie M. Neway, "The Role of the Information Specialist in Academic Research," Online Review 6, no. 6 (Dec. 1992): 527-35.

22. Horner and Thirlwall, "Online Searching," 227.

23. Stephen Lehmann and Patricia Renfro, "Humanists and Electronic Information Services: Acceptance and Resistance," College \& Research Libraries 52, no. 5 (Sept. 1991): 411.

24. Harriet Lönnqvist, "Scholars Seek Information: Information-Seeking Behaviour and Information Needs of Humanities Scholars," in Papers Presented at the International Federation of Library Associations (IFLA) 56th General Conference, Joint Workshop Papers, Booklet 7 (1990). ERIC Document 329288. 


\section{INFORMATION COMES IN ALL}

\section{SHAPES AND SIZES}

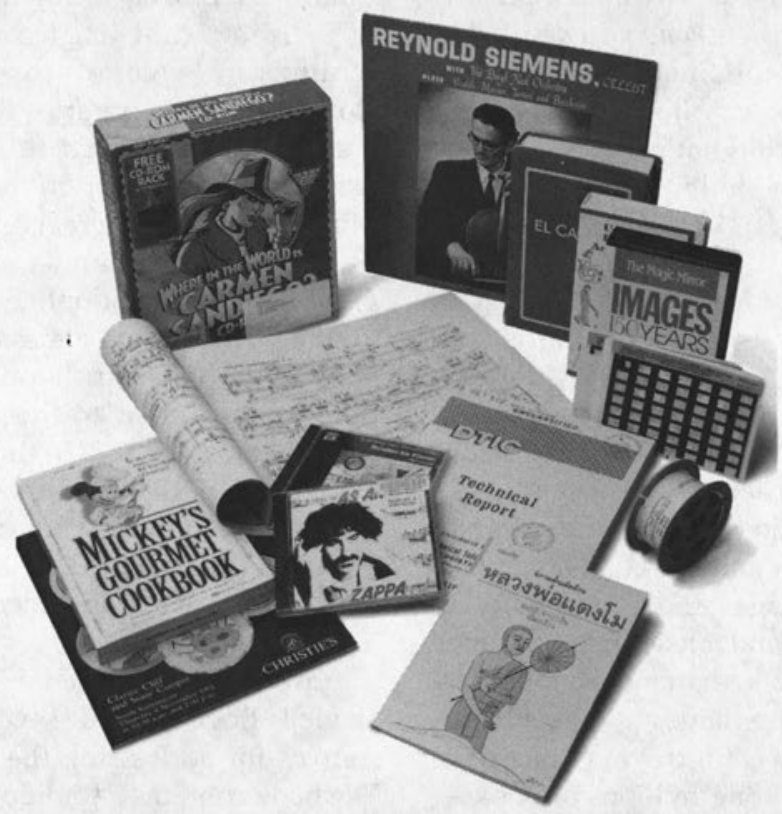

\section{OCLC's TECHPRO Service catalogs it all}

With library resources so stretched, it's challenging to keep your cataloging upto-date. And it's frustrating, because uncataloged materials are inaccessible to your patrons.

OCLC's TECHPRO Service can help. Since 1985, we've offered solutions for libraries that have cataloging backlogs or need ongoing cataloging support.

- Customized cataloging and physical processing to match your specifications

- Cataloging for all bibliographic formats and many languages

- Quality cataloging at prices that can reduce your overall cataloging costs Contract cataloging for books, serials, scores, non-print items, foreign language materials and more-it's cataloging in all shapes and sizes-from OCLC's TECHPRO Service.

1-800-848-5878, ext. 4386

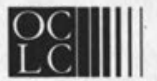

